\title{
Congenital Displacement of Temporal Cortex into the Central Spinal Canal
}

\author{
DAVID A. SILVER AND DAVID M. ROBERTSON
}

\begin{abstract}
SUMMARY: This is a report of the first recorded observation of displacement of temporal cortex into the central spinal canal in an infant with the Arnold Chiari malformation, platybasia, aqueductal atresia, hydrocephalus and meningomyelocele. The combination of an $a b$ sent tentorium, absent right cerebellar hemisphere and malformed fourth ventricular roof provided the anatomical background for this unique event.
\end{abstract}

RÉSUMÉ: Il s'agit de la première observation rapportée de déplacement du cortex temporal dans le canal spinal central chez un enfant avec une malformation de type Arnold Chiari, platybasie, atrésie de l'aqueduc, hydrocéphalie et méningomyelocèle. La combinaison d'un tentorium absent, d'un hémisphère cérébelleux droit absent, et d'une malformation du toit du 4 e ventricule fournissant l'arrière plan anatomique de cet événement unique.

From the Department of Pathology, Queen's University and Kingston General Hospital, Kingston, Ontario, Canada.

Reprint requests to D. M. Robertson, M.D., De partment of Pathology, Richardson Laboratory, Queen's University, Kingston, Ontario, Canada K7L 3 N6.

\section{CASE REPORT}

A full term male infant was delivered of a Gravida O Para O Aborta O 15 year old mother by breech extraction after foot presentation. The infant exhibited marked platybasia and a meningomyelocele from the lower thoracic level to the sacrum. There was motor paralysis and sensory loss below T9. The infant lived 5 days; terminally the meningomyelocele became infected.

At autopsy the squamous portion of the occipital bone was flattened, subtending an angle of 80 degrees with the vertebral column. Removal of the occipital bone and a laminectomy of the vertebral column demonstrated the abnormal shape of the inferior surface of the temporal and occipital lobes conforming to the abnormal shape of the occipital bone, the absence of a tentorium and virtually no posterior fossa. Markedly hypoplastic cerebellum and brainstem were found in the upper cervical canal. Displaced left temporal lobe tissue was also noted in the upper cervical canal (Fig. 1).

Subsequent dissection of the upper spinal cord and brainstem demonstrated the absence of the right cerebellar hemisphere exposing the abnormal fourth ventricular roof. The displaced temporal lobe tissue lay dorsal to the roof of the fourth ventricle and then invaginated the roof (Fig. 2).

Serial cross section of the spinal cord demonstrated a mass in the central canal (Fig. 5) which was in continuity with temporal lobe tissue cephalad and extended the length of the spinal cord, terminating as a flap of $\tan$ colored tissue exposed on the upper surface of the meningomyelocele (Fig. 1).

Microscopic examination confirmed the origin of this mass as degenerated periventricular temporal cortex covered by vascular tissue of meningeal origin. The hippocampus could be identified (Figs. 3A, 3B). At the level of the fourth ventricle the temporal lobe tissue invaginated the abnormal gliotic ventricular roof (Figs. 4A, 4B). Subsequent spinal cord sections demonstrated a double layered mass within the central canal, the inner layer derived from the temporal lobe and the outer layer derived from the roof of the fourth ventricle (Figs. 5A, 5B).

Other abnormalities noted were microgyria, hydrocephalus secondary to aqueductal atresia, enlarged 


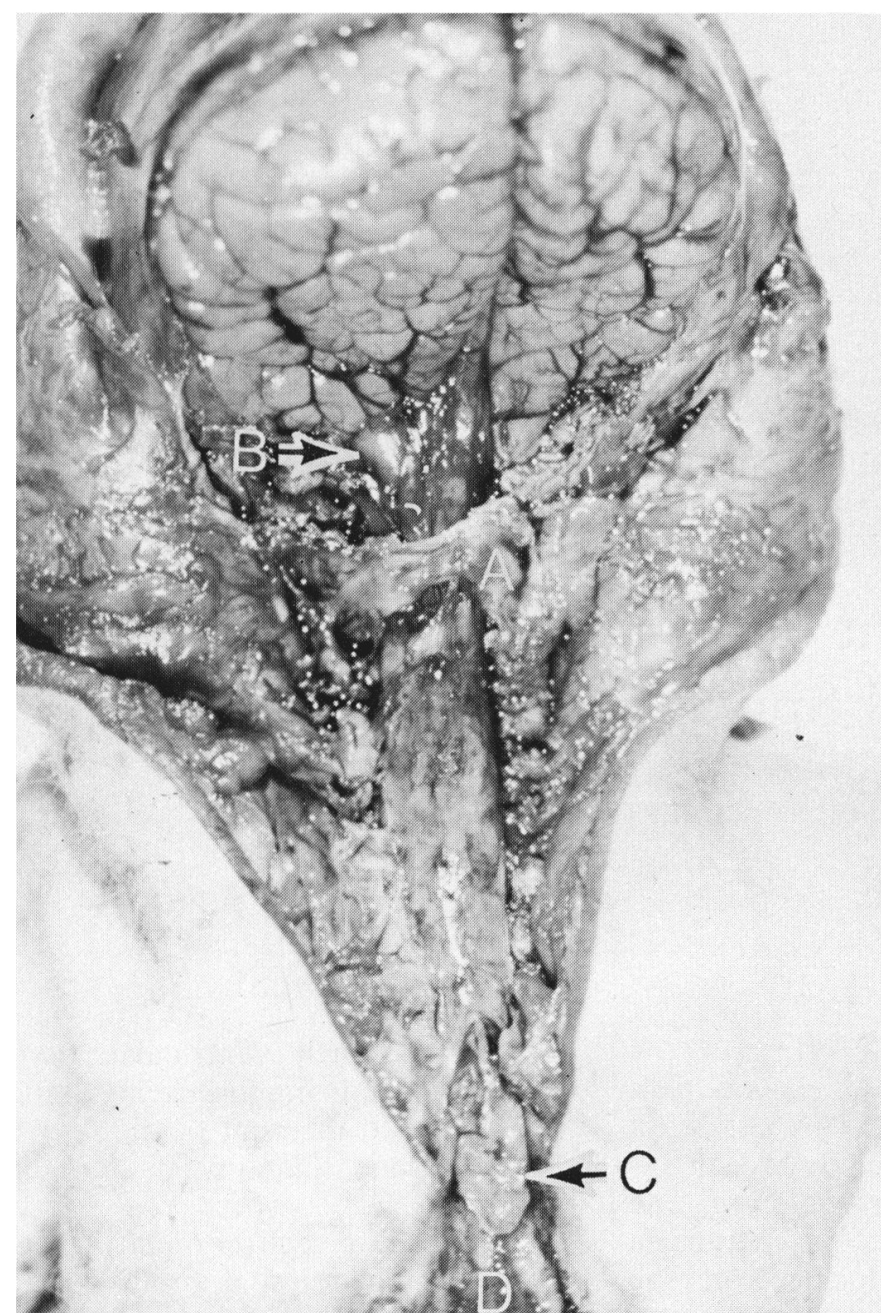

Figure 1-Posterior view of brain and spinal cord after removal of the occipital bone and vertebral column. The atlas (A) is preserved. Temporal cortex (B) is displaced through the foramen magnum. Hypoplastic cerebellum and brainstem are in the upper cervical canal covered by meninges. A flap of tissue (C) exits from a dorsal defect in the spinal cord and lies on the upper surface of the meningomyelocele (D).

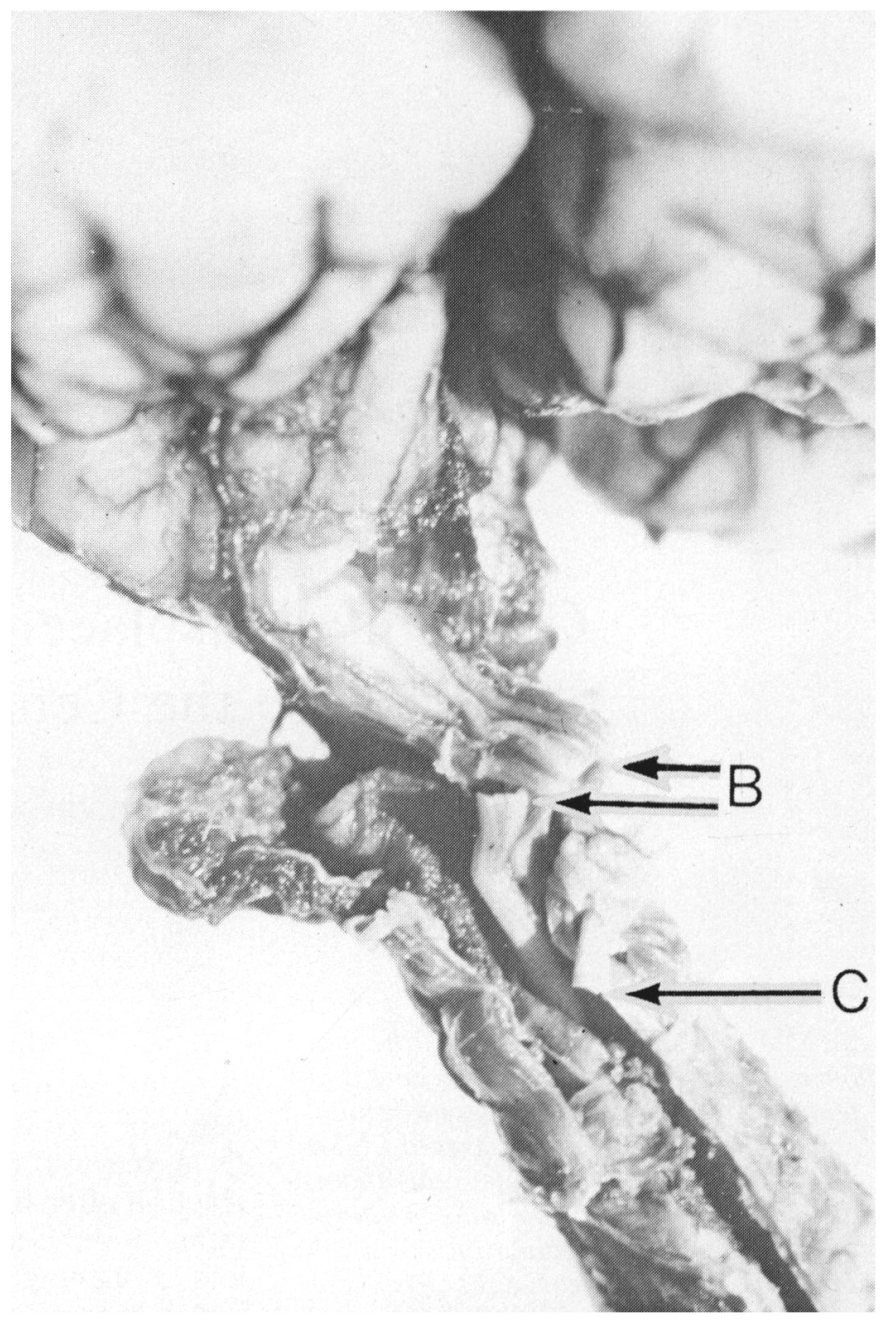

Figure 2-Posterior view of brainstem. The right cerebellar hemisphere is absent and the left cerebellar hemisphere (A) and brainstem are hypoplastic. Displaced temporal cortex which has been cut at (B), lies posterior to the exposed roof of the fourth ventricle and then dips into the upper cervical cord through the roof of the fourth ventricle. The cerival spinal cord has been incised along the posterior raphe $(C)$. massa intermedia, malformation of the quadrigeminal plate and absence of the left inferior olive.

\section{Comment}

This case demonstrated the features of the Arnold Chiari malformation, with platybasia, hydrocephalus and meningomyelocele. This constellation of abnormalities is recognized to occur together and their pathogenetic mechanisms is not well understood (1).

The additional feature of note was displacement of temporal cortex into the central canal which could not have occurred unless the normal barriers to temporal lobe displacement were absent. The absence of the tentorium permitted the displacement of temporal lobe tissue through the virtually non-existent posterior fossa. The right cerebellar hemisphere was absent and the remainder of the cerebellum and brain stem was hypoplastic allowing room for the temporal lobe tissue to occupy a dorsal position in the upper cervical canal. In the progressively narrower vertebral canal the tem- poral lobe tissue pushed through the roof of the fourth ventricle carrying a diverticulum of the fourth ventricular roof. The resulting double layered mass came to lie in the central canal of the spinal cord. It is remarkable that descent through the central canal extended to the level of T10 where the lower end of the mass protruded into the meningomyelocele.

\section{REFERENCES}

CONGENITAL MALFORMATIONS, Warkany, J., p. 220. Year Book Medical Publishers, Chicago, 1971. 

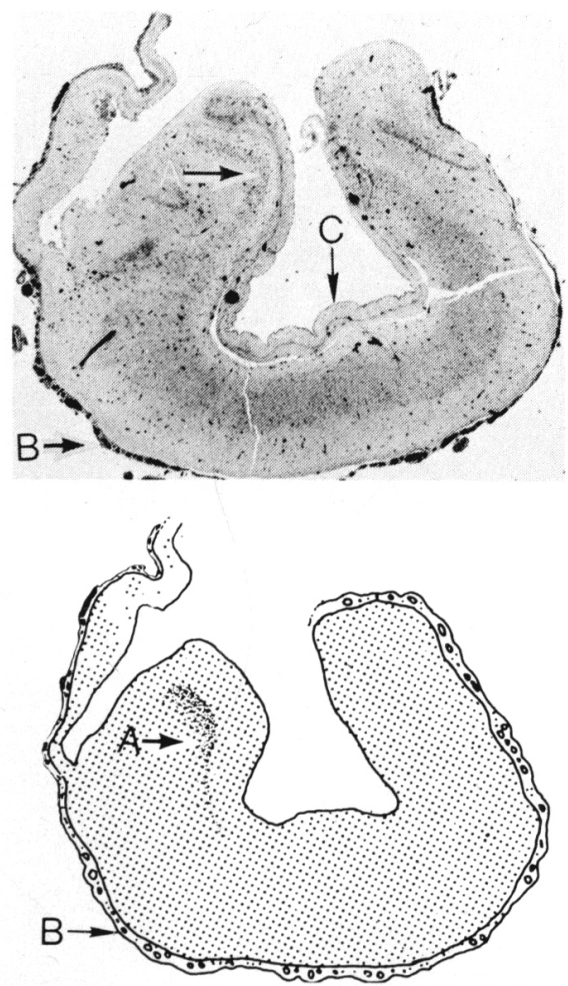

Figures $3 A, 3 B$-Proximal cross section of the displaced temporal cortex near the foramen magnum. The hippocampus (A), meningeal covering (B) and the ependymal lining of the temporal hom of the lateral ventricle $(C)$ can be identified. $\times 8$.
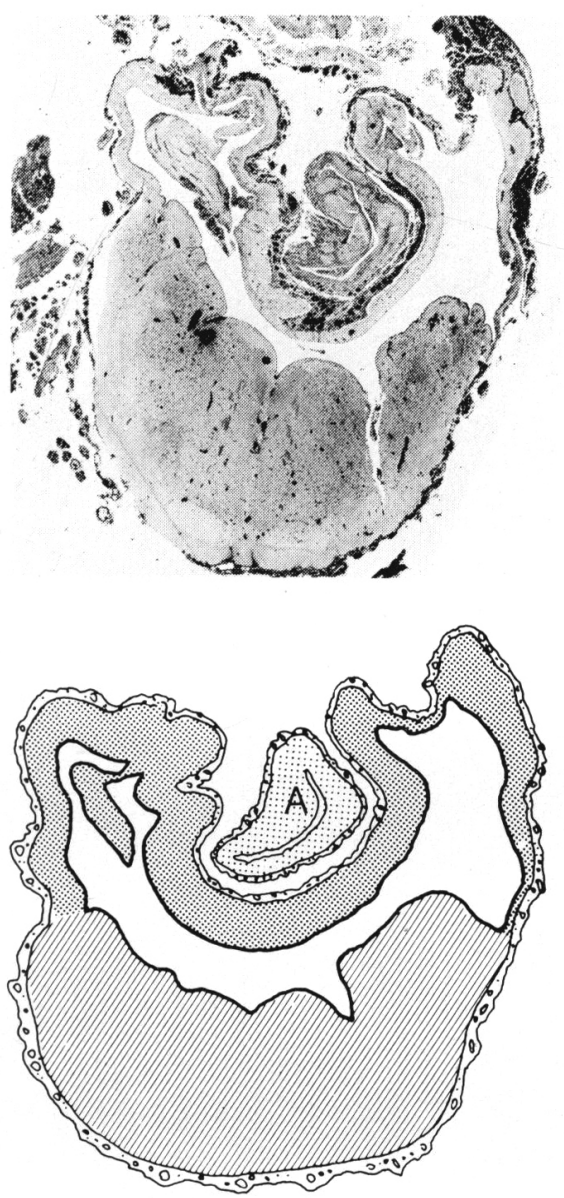

Figures $4 A, 4 B$-Cross section of the fourth ventricle through the upper medulla. The displaced temporal cortex (A) invaginates the roof of the fourth ventricle. $X 9$.
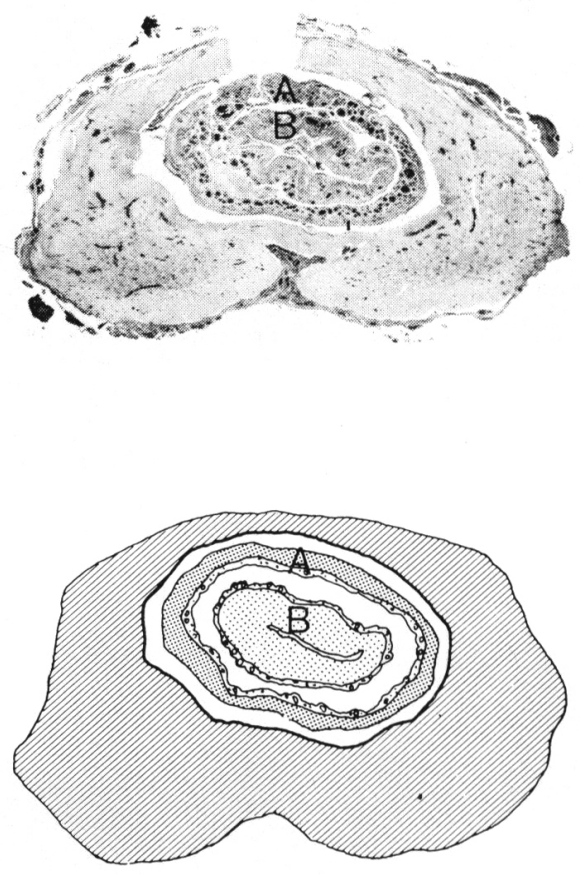

Figures $5 A, 5 B$-Cross section of the thoracic spinal cord. The central canal which is lined by ependyma contains a double layered mass. The outer layer (A) is derived from the roof of the fourth ventricle. The inner layer (B) is derived from the temporal lobe. The spinal cord has been incised along the posterior raphe. $\times 9$. 